\title{
Teaching and Learning English at Tertiary Level: Revisiting Communicative Approach
}

\author{
Kun-huei Wu \\ English Department, Aletheia University, Taiwan \\ Email: au4284@mail.au.edu.tw
}

\begin{abstract}
This study aims to discuss students' and teachers' awareness of various aspects of Communicative Language Teaching (CLT) and in light of the results, consider the pedagogical implications. Participants consist of nine non-native English teachers and 286 students in Taiwan's universities. Data was collected through an attitude scale and interviews with the participants. Analytical results revealed that most of the students preferred the communicative-learning teaching approach as a means to improve their English proficiency. Both students and teachers showed positive attitude with some reservation toward four domains of CLT: group/pair work, grammar, student/teacher role, and peer/teacher correction. The results also showed that the difficulties - teacher-related, student-related, and educational-system related-encountered by non-native English teachers were complex. Teacher-related constraints included teachers' low confidence in spoken English, deficiency in strategic and sociolinguistic competence, unfamiliarity with the target culture, lack of proper training in CLT, and low willingness to prepare communicative materials. Student-related constraints were mainly due to students' insufficient proficiency, and educational-system related limitations consisting of large classes and grammar-based examinations. The findings of this study, which corroborated those of previous studies, suggest that many of the difficulties encountered by both Taiwanese students and English teachers over the past decades still persist to this day.
\end{abstract}

Index Terms-Communicative Language Teaching (CLT), attitude, NNEST, NEST

\section{INTRODUCTION}

Although many people are opposed to the idea of English as an international "lingua franca", it is generally acknowledged that English has become one of the most accepted medium of communication. Language communication ability plays an important role in the global village, in which economists emphasize that English proficiency is a form of human capital in the workplace (McManus, 1985). Taiwan aims to be one of the major economic partners in the world; language learners are therefore highly expected to emulate the communicative skills of native speakers. The influence of English as a global language compelled the Ministry of Education (MOE) in Taiwan to reform its English education policy. In 2001, English programs were implemented in the elementary school curriculum, aiming to provide a natural and enjoyable language learning environment. Before that, students started to learn English as one of their compulsory courses in junior high school. Due to the pressure of entrance exams, most students' learning experience is far from being natural and enjoyable. Accordingly, the average English proficiency among students, ranging from junior high school to university students, is still quite low when it comes to communicative use.

Beginning in the 1970s, voice for improving students' communicative competence became louder; the thought of adopting another practical teaching method emerged. The Grammar-Translation and Audiolingual have been two of the most popular teaching approaches in Taiwan. As a result, communicative competence has long been neglected by Taiwanese teachers and students. Communicative Language Teaching (CLT) is one of the methods which accentuates its goal of language teaching on communicative competence (Hymes, 1972). It is seen as a teaching innovation and has widely spread over the past two decades. CLT is arguably today's most popular teaching method in the field of English language teaching (ELT). From its introduction into discussions of language and language learning, the term "communicative competence" has prompted reflection. Although it is extensively practiced in the English as a second language (ESL) setting, CLT is not successfully applied in the English as a foreign language (EFL) setting. English teachers from countries such as China, Greece, South Korea, and Turkey have made attempts to implement CLT; however, research has shown that English teachers from these countries have faced many constraints that have hindered them from fully adopting this approach (Burnaby and Sun, 1989; Eveyik-Aydin, 2003; Karavas-Doukas, 1996; Li, 1998). Some of the more common constraints include large classes, grammar-based examinations, teachers' low English proficiency and lack of cultural knowledge, lack of communicative teaching materials, and students' low English proficiency. The results from the above studies affirmed the importance of understanding and taking into account teachers' and students' attitudes toward an innovative teaching approach (CLT) when attempting to implement such an approach.

\section{A. Communicative Language Teaching}

Communicative Language Teaching is an approach which highlights communicative competence as the goal of 
language teaching. It is one of the communication-based English teaching approaches emphasizing the pragmatic, authentic, and functional use of the target language for meaningful purposes. (Brown, 1994) According to Larsen-Freeman (2000), CLT consists of the following characteristics. Its primary goal is to develop communicative competence in language learners, enabling them to communicate using the target language, which requires not only knowledge of linguistic form and meaning but also function. Language learners acquire the ability to differentiate between the various functions that a form may have and to choose the appropriate form that is suitable to the given context. They learn to negotiate meaning in a conversation. In CLT, the role of the teacher is that of a facilitator, advisor, and 'co-communicator,' and the role of the students is to communicate by participating in meaning-negotiation activities and to manage their own learning. Students work, not only as a whole group, but also in pairs and small groups. Activities considered truly communicative are those that include an information gap, choice, and feedback (Morrow, 1981, as cited in Larsen-Freeman, 2000). Information gap refers to the need of one interlocutor to obtain an unknown piece of information from the other. Choice is being able to decide what one will say and how one will say it, and feedback from participants in a conversation ascertains that the communication is purposeful.

CLT focuses on language functions over forms; therefore, a functional syllabus, which is organized according to functions such as introducing oneself, making requests, asking for information, apologizing, and congratulating, is usually used and is accompanied by authentic teaching materials. Language activities take place at the discourse level (e.g., looking at the cohesion and coherence of paragraphs) and seek to integrate the four language skills (reading, writing, listening, and speaking). Language is for the purpose of communication, not just an object of study. Consequently, the target language is used not only for communicative activities but also for instruction, minimizing the usage of the native language.

CLT evaluates both fluency and accuracy. Informal assessment can take place when the teacher is being the advisor and co-communicator. Integrative tests with a real communicative function are used. Errors of form are seen as a natural part of developing communicative competence; hence, they are overlooked when the focus is on fluency.

\section{B. Problems of Adopting CLT}

English is one of the most widely taught foreign languages in Taiwan. Students, ranging from elementary school to university, are requested to learn English as an obligatory course for different lengths of time. The central argument lies on the fact that university students, who have usually learned English for more than six years, have difficulties both in understanding and in making themselves understood as they communicate with English native speakers. Huang (1990) noted that the majority of the language learners are capable of learning to read the target language with varying degrees of success, but when it comes to oral communication, most of them become hopelessly dysfunctional. The traditional translation-grammar teaching/learning approach has caused both teachers and students to neglect the value of oral communication. Training students to obtain good grades on English tests would be one of the most vital criteria for being a good English teacher. In short, teachers and students share one common and identical mission: how to get good marks in entrance exams in order to be admitted into the ideal university. It is generally acknowledged that the higher the marks, the higher the students' English proficiency. However, the negative impact that has emerged from this teaching/learning strategy cannot be overstated. Examination-guided instruction and the premium placed on lecturing on selected textbook materials have led to failure in learning real-life communicative English. Many university students with high marks on the TOEFL have difficulties communicating with English-speaking people. Due to such discrepancies, an oral section has been added to the TOFEL test. This dramatic change has caused language learners to rethink their learning strategies.

In 1984, an inciting and widely influential article came out in defense of the communicative approach (Li). It argued against the traditional methods and questioned Chinese teachers' beliefs in regards to the language teaching and learning process. Like Taiwan, the dominant teaching method in China was based on the audiolingual and grammar-translation approaches to language teaching, which emphasized pronunciation/intonation training and oral practice through pattern drills for the purpose of developing good verbal habits; there was also a strong focus on grammar analysis, use of translation, rote memorization of vocabulary, intensive reading skills, and writing (Hu, 2002). Calling into question the prevailing notion that the form of language must be acquired first before its usage, Li contended that to learn the target language, one must use it. He asserted that the language of study must be "authentic, appropriate, and 'global'," meaning that it ought to be relevant and context-sensitive as well as whole and multidimensional. Grading of materials ought to be based on students' control of tasks and not on grammar and vocabulary. He further argued against the principle of 'learning sparingly but well,' asserting that teachers should not hold back input from the students but rather, give them a large amount of it, unafraid that the students will not be able to digest all the language data. Calling for a focus on tasks rather than on text, grammar, and vocabulary, he also affirmed the strength of CLT in its integration, not compartmentalization, of all four language skills. He argued that language classrooms ought to be student-centered, based on student needs and goals, rather than teacher-centered. Furthermore, he challenged the traditional schools of thought which view language teaching as imparting knowledge and language learning as receiving knowledge; he maintained that language learning is an active development process where learners need to take initiative and be active in the learning process. Finally, he asserted that effective communication-linguistic accuracy and sociolinguistic appropriateness-should be the criterion for judging performance, not the ability to memorize grammatical rules and a large number of vocabulary words. As a result of such discontentment with the traditional teaching methods, the 
Chinese government was compelled to begin reforming the nation's ELT. One of the major changes was the replacement of the structural syllabus by a functional one in 1992, which set communicative competence as its primary aim. This was to be accomplished "by training in listening, speaking, reading and writing, to teach students in order to gain basic knowledge of English and competence to use English for communication" (English Teaching Syllabus, 1992 , as quoted in Liao, 2000).

However, despite the reforms, the traditional method has remained predominant in many classrooms, albeit to a lesser extent than two decades ago. Many articles have explored the reasons for this reluctance to adopt CLT (Anderson, 1993; Campbell \& Zhao, 1993; Liao, 2000). Anderson (1993) identified the following as obstacles to the implementation of CLT: heavy demands (due to the lack of training, texts, and materials) placed on teachers, students' lack of readiness, the difficulty of assessing communicative competence, and the need to prepare students for grammar-focused examinations. Campbell and Zhao (1993) observed that this reluctance to change has to do with the highly centralized education system, perceptions of teachers and students, teachers' limited knowledge of the target culture, and the lack of attention paid to the cultural context. Liao (2000) noted that the difficulties are related to teachers' lack of language proficiency and familiarity with the new method. Moreover, the influence of Chinese educational traditions has been difficult to overcome.

The above-mentioned English teaching/learning problems are seen as a reflection of those factors which affect EFL/ESL teaching in Taiwan. Traditional EFL instruction in Taiwan focuses on teacher-centered, grammar-translation, audio-lingual, and exam-oriented approaches that rarely meet students' needs when they communicate with English speakers or study abroad (Wang, 1994; Yang, 1978). Finding the way to improve students' weaknesses while communicating with English-speaking people is of great importance for both teachers and students in Taiwan.

\section{Related Studies on Attitude toward CLT}

Of central importance in understanding the feasibility of implementing CLT is teachers' attitudes toward this innovative approach to language teaching. As Li (1998) puts it, "How teachers as the end users of an innovation perceive its feasibility is a crucial factor in the ultimate success or failure of that innovation" (p. 698).

In their study on the effect of language context on Chinese teachers' views of CLT, Burnaby and Sun (1989) found that teachers perceived the communicative approach as more suitable for those planning to study or live in an English speaking country (English as a second language (ESL) context), but not for those, especially English majors, who planned to remain in China (English as a foreign language (EFL) context). For the latter, the traditional methods were perceived to be more appropriate, given their specific needs and learning goals. The study also revealed that teachers viewed their non-native English speaking teacher identity as a limitation (e.g., lack of familiarity with authentic texts, lack of knowledge in regards to appropriate cultural contexts, and no target language "intuition"). Furthermore, the pressure to teach to the grammar-focused examinations, the clash of two different teaching philosophies, large classes, lack of resources, and the low status associated with teaching language skills were all seen as constraints on the application of CLT.

Karavas-Doukas (1996) examined Greek secondary school English teachers' attitudes toward CLT and found that most had mildly favorable to favorable attitudes towards this approach. However, upon observing some of these teachers in the classroom, the researcher found that their teaching practices did not correspond with their attitudes toward CLT. There was an emphasis on form, the classes were teacher-centered, and there were no group activities. In this case, the discrepancy was caused by a lack of understanding of CLT principles. The author made note of the importance of not neglecting teachers' beliefs and attitudes prior to the introduction of a new teaching method. Li's (1998) study on South Korean secondary school English teacher's perceived difficulties in adopting CLT showed results similar to the two studies above. Perceived difficulties specifically related to teachers included teachers' deficiency in spoken English and strategic and sociolinguistic competence, lack of training in CLT, limited opportunities for retraining in CLT, misconceptions about the approach, and lack of time and expertise to develop communicative materials. Perceived educational system constraints consisted of large classes, grammar-based examinations, and lack of funding and support. Perceived difficulties caused by CLT itself included an inadequate account of EFL teaching context and the lack of effective and efficient instruments for assessment. Finally, perceived difficulties related to students included low English proficiency, little motivation for communicative competence, and resistance to class participation. This last point is further supported by two studies investigating student's attitudes toward CLT. Matsuura, Chiba, and Hilderbrandt's (2000) study of Japanese students revealed that the latter preferred traditional methods-learning isolated skills, focusing on accuracy, and the teacher-centered approach. The Chinese students in Rao's (2002) study preferred non-communicative activities such as audiolingual drills and workbook type drills over communicative activities.

Showing similar results, Eveyik-Aydin's (2003) examination of Turkish secondary school English teachers' attitudes toward CLT indicated that most had a favorable attitude with some reservations. These reservations concerned constraints that were caused by the educational system-large classes and having to stick to the curriculum; teachers' beliefs and educational values; and the students-low proficiency, fear of making mistakes, and the pressure of having to pass national examinations. Because of the crucial role teacher's attitudes and beliefs toward CLT play in the ongoing reforms in ELT in Taiwan, this paper will attempt to conduct an investigation of selected teachers' and students' attitudes toward the implementation of this approach. Furthermore, it will explore the difficulties encountered by these 
teachers in applying the principles of CLT.

\section{MEthodology}

\section{A. Research Instrument}

Data were collected through the Communicative Language Teaching Attitude Scale (COLTAS) that was developed by Eveyik-Aydin (2003). Although this instrument was intended for the Turkish EFL context, it is, nevertheless, applicable to the Taiwan EFL context because of the similarities in both settings and also because the statements are not so specific as to limit it to one particular setting.

This instrument is a five-point Likert type attitude scale consisting of 36 statements developed based on the fundamental characteristics of CLT and categorized into four domains: group/pair work activities, place of grammar, student/teacher role, and peer/teacher correction (see Appendix A). Of all the statements, half of them have been designated as "negative" because they support the traditional perspective on language teaching, while the other half have been designated as "positive" because they reflect the principles of CLT. In this instrument, the positive items on the scale, those that reflect the principles of CLT, were assigned a high score of 5 for "strongly agree (SA)" down to a low score of 1 for "strongly disagree(SD)." The negative items on the scale, those that reflect a traditional view of language teaching, were assigned a reverse score of 1 for "strongly agree" up to 5 for "strongly disagree." Thus, the participants who were more in favor of the communicative approach would have selected a larger number of scores between 4 and 5, and those who were more in favor of the traditional approach would have selected a larger number of scores between 1 and 2. The higher the scores obtained on COLTAS, the more favorable were the participants' attitudes toward CLT, and the lower the score, the less favorable the participants' attitudes. Scores for each participant were calculated and placed within the following categories. Scores between 180 and $144(36 \times 4)$ revealed a very favorable attitude toward CLT, whereas scores between 36 and $72(36 \times 2)$ revealed a very unfavorable attitude. A score of 108 (36x3) revealed a neutral attitude toward CLT. Scores between 109 and 143 showed a favorable attitude with some reservations toward CLT, while scores between 73 and 107 reflected unfavorable attitudes with some reservations.

\section{B. Research Questions}

To enhance students' communicative competence, it is important to develop student-centered learning; to cultivate a range of learning strategies and study skills; to develop skills in intercultural communication, and to increase cultural awareness. It is teachers' mission to inspire students and to strengthen their confidence during the learning process in a foreign language classroom. But, it is more important to deeper understand students' perception before implementing the innovative teaching approach. In recent years, language teachers have made effort to stay away from traditional teacher-centered, grammar-oriented teaching and move toward student-centered approaches. This shift from grammar-translation methodology to communicative approach has been one significant characteristic of language education. For this reason, the following two research questions were presented as follows:

1. What are the selected teachers' and students' awareness of the shift from grammar-oriented teaching approach to communication-oriented teaching approach?

2. What are the difficulties facing non-native English teachers in teaching English communicatively in the Taiwan EFL context?

\section{Interview Questions}

After completing COLTAS, closed and open-ended interview questions were sent to the selected teachers in order to determine the types of difficulties they face in implementing CLT in their classrooms. The interview questions were adapted from Li's (1998) questionnaire in her study on South Korean secondary school English teacher's perceived difficulties in adopting CLT. There are 12 "yes" or "no" questions related to common difficulties faced by EFL teachers in the implementation of CLT, an open-ended question asking participants to explain any "yes" responses, and a final question asking them to identify other difficulties not already mentioned (see Appendix B). Analysis of the interviews was conducted by placing the data within three main categories: teacher-related, student-related, and educational system-related difficulties in the implementation of CLT. These categories were derived from the questions themselves. Questions one, two, three, ten, eleven, and twelve ask about difficulties related to teachers; four and five inquire into difficulties associated with students; and questions six, seven, and eight solicit information related to the educational system.

As with the administration of COLTAS, to ensure that the participants fully understood the questions, they were also encouraged to ask for clarification through e-mail. In addition, terms with which the participants were less familiar were defined and included in the interview. As to students' interview, most of the questions are based on the questionnaire (See Appendix A). Besides, they were also asked to express their perception toward non-native English teachers in the implementation of CLT.

\section{Participants}

In March 2010, COLTAS was administered to nine English teachers and 286 students. Both teachers and students are affiliated to three universities located in northern, central and southern Taiwan. All of the teachers are non-native 
English teachers, six female and three male, who were born, raised, and obtained their Master or PhD degree in Taiwan. Three of them are associate professors, three assistant professors, and three lecturers. Their average teaching experience is over six years. They never studied abroad but had some experience traveling in different parts of the world. Some of the participants requested that the interview be conducted anonymously, thus the participants are labeled as F1, F2, F3, F4, F5, F6, M1, M2, M3 respectively. (See Table 1)As to students, all of them are seniors of English Department and have been taught by one of the nine English teachers in this study. They were studying in the universities located in northern $(n=108)$, central $(n=98)$, and southern $(n=80)$ part of Taiwan; 201 of them are females, and 85 males (See Table 2). The main reason of choosing seniors of English Department as the selected participants is based on the assumption that they share one similar goal --- to improve their English proficiency. Besides, they are soon facing the challenge of demonstrating their communication skill and language proficiency in the working places. When asked about their previous learning experience in the language classroom, they showed stronger willingness to express their opinions.

TABLE 1

BACKGROUND OF THE TEACHERS

\begin{tabular}{lllll}
\hline \hline Participant & Gender & Years of teaching experience & Position & location of University \\
\hline \hline F1 & Female & 8 & Associate prof. & Northern Taiwan \\
F3 & Female & 4 & Assistant prof. & \\
& Male & 11 & Lecturer & Central Taiwan \\
\hline F4 & Female & 10 & Associate prof. & \\
F5 & Female & 5 & Assistant prof. & Southern Taiwan \\
M1 & Female & 12 & Lecturer & \\
F2 & Female & 7 & Associate prof. & \\
M3 & Female & 3 & Assistant prof. & lecturer \\
\hline
\end{tabular}

TABLE 2

BACKGROUND OF THE STUDENTS

\begin{tabular}{|c|c|c|c|}
\hline Class & Gender & Number of student & location of university \\
\hline \multirow[t]{2}{*}{ Freshmen } & Female & 74 & Northern Taiwan \\
\hline & Male & 34 & \\
\hline \multirow[t]{2}{*}{ Freshmen } & Female & 62 & Central Taiwan \\
\hline & Male & 36 & \\
\hline \multirow[t]{2}{*}{ Freshmen } & Female & 47 & Southern Taiwan \\
\hline & Male & 33 & \\
\hline
\end{tabular}

\section{DATA ANALYSIS}

Results from the Attitude Scale

The results showed that both teachers and students had a favorable attitude toward CLT. For teachers, three of them had a very favorable attitude, while the other four had favorable attitudes with some reservations. Only two participants showed an uncertain attitude. For students, 98 of them had a very favorable attitude, 124 had favorable attitudes with some reservation, 43 showed an uncertain attitude, 12 had unfavorable attitudes with some reservation, and 9 had very unfavorable attitudes. Scores tabulated to determine participants' attitudes toward each of the four domains revealed that, overall, most of the participants had favorable attitudes with reservations toward all four domains (see Table 3).

TABLE 3

DISTRIBUTION OF THE SCORES OBTAINED BY THE PARTICIPANTS ON COLTAS

\begin{tabular}{l|llll}
\hline \hline Participants & $\begin{array}{l}180-144 \\
\text { Very favorable } \\
\text { attitude }\end{array}$ & $\begin{array}{l}143-109 \\
\text { Favorable attitude } \\
\text { with } \\
\text { some reservations }\end{array}$ & Uncertain & $\begin{array}{l}107-73 \\
\text { Unfavorable attitude } \\
\text { with } \\
\text { some reservations }\end{array}$ \\
\hline $\begin{array}{l}\text { Teachers } \\
\text { Number of Participants }\end{array}$ & $3(33 \%)$ & $4(55 \%)$ & $2(22 \%)$ & -- \\
\hline $\begin{array}{l}\text { Students } \\
\text { Number of Participants }\end{array}$ & $88(30 \%)$ & $134(46 \%)$ & $43(15 \%)$ & $12(5 \%)$ \\
\hline
\end{tabular}

\section{A. Feedback from the Teachers' Interview}

Results from the interview were analyzed in light of three major categories of difficulties faced by EFL teachers in implementing CLT: teacher-related, student-related, and educational system-related.

1. Teacher-related Difficulties

The participants identified several constraints that were directly related to them as teachers. These included teachers' lack of confidence in spoken English, deficiency in strategic and sociolinguistic competence, lack of willingness to prepare communicative materials, lack of training in CLT, and lack of cultural knowledge (see Table 4). Of these, teachers' low confidence in spoken English and lack of cultural knowledge were selected most often. 
Lack of Confidence in Spoken English

Eight of the participants indicated that teachers' deficiency in spoken English is a source of difficulty when attempting to implement CLT in the classroom. Reasons given to explain this included teachers' limited vocabulary, lack of attention to their own spoken English, and uncertainty about speaking the language correctly. The following are comments from M1, F2, and F4.

M1: I feel I have a lot of problems to speak English accurately. Sometimes I can speak it fluently, but I am not sure it is in an appropriate way. I feel frustrated and lack of confidence in the class sometimes.

F2: Although I know the definition of vocabularies, I have difficulties finding the suitable collocations as expressed by native speakers. Sometimes I even doubt if I am qualified to be an English teacher.

F4: I am not very satisfied with my own English proficiency, and I feel frustrated when I fail to answer students' questions.

TABLE 4

REPORTED DIFFICULTIES IN IMPLEMENTING CLT

\begin{tabular}{ll}
\hline \hline Teacher & Number of participants \\
\hline Lack of confidence in spoken English & 8 \\
Lack of sociolinguist competence & 6 \\
Lack of willingness to prepare communicative materials & 3 \\
Lack of training in CLT & 6 \\
Lack of cultural knowledge & 7 \\
\hline Students & Number of participants \\
\hline Low English proficiency & 9 \\
Passive learning style & 7 \\
\hline Educational system & Number of participants \\
\hline Large classes & 7 \\
Grammar-based examinations & 6 \\
Lack of authentic teaching materials & 3 \\
\hline
\end{tabular}

Lack of Cultural Knowledge and Sociolinguistic Competence

Because cultural knowledge is part of sociolinguistic competence, these two constraints were combined under one heading. Six of the participants reported that deficiency in sociolinguistic competence was an impeding factor in their decision to apply CLT, and seven of them reported that their lack of cultural knowledge was also a constraint.

M2: I wish I have chance to study abroad to feel cultural difference.

F6: It is hard to explain idioms or some expression without exposure to culture different from our own.

F3: I feel guilty myself since I have limited knowledge about foreign culture; I did have some traveling experience, but I don' think it is enough.

Lack of Willingness to Prepare Communicative Materials

Three participants reported that having little willingness to prepare materials for communicative lessons was also an obstacle to the implementation of CLT. This was attributed to a heavy teaching load and having less proficient students in the classroom.

F1: Preparing teaching material is a time-consuming task, I have to teach different courses and I don't have much time left to do this job.

Lack of Training in CLT

Six participants indicated that lack of training was also a constraint. Their responses revealed that there was a lack of focus on teaching methodology in their teacher training. As can be seen, despite having had several years of teaching experience, participants revealed that they have had little training in CLT.

M3: Training is a must for all teachers, but I seldom find similar training program.

2. Student-related Difficulties

The second category of difficulties involved students. The participants identified two student-related difficulties in adopting CLT: low English proficiency and a passive learning style. The former was seen by the participants as more of a constraint than the latter (see Table 4).

Low English Proficiency

Nine of the participants considered students' low English proficiency a major obstacle in applying CLT. They reported that students were lacking in their ability to understand and express themselves in the target language, despite having a large vocabulary, and that this low communicative proficiency was due to the curriculum's strong focus on grammar. One of the female English teachers pointed out that teachers are asked to speak English throughout the entire class, but most of the time students can't understand what they say. Then they have to translate it into Chinese, so for half of the lesson teachers end up speaking Chinese. Though the students have a large vocabulary, they cannot express themselves properly. Most of them spend a large amount of time on grammar; they don't practice speaking a lot.

Passive Learning Style

Seven participants reported that students' passive learning style was a constraint on teachers' use of CLT. The main reasons expressed for this was the lack of opportunities for students to interact in English and again, the impact of a strong emphasis on grammar. Closely related to this issue of students' passive learning style is students' motivation, 
which the participants also acknowledged as a constraint. One of the male teachers pointed out that students have very few opportunities to interact in English outside the classroom, and because of the examination system, they have to learn grammar and recite the words. At the very beginning, most of the students like to learn English, but later on, they lose interest.

3. Educational System-related Difficulties

The third category of difficulties faced by the teachers in applying the principles of CLT was the educational system. This included large classes, grammar-based examinations, and lack of funds to provide for resources such as authentic teaching materials (see Table 4).

Large Classes

Seven participants indicated that large classes were a major impediment to teachers' attempts at implementing CLT. In Taiwan's Universities, English is an obligatory course; however, the number of students in each class is usually about 50 students or so, which means that students' learning efficiency suffers.

\section{Grammar-based Examinations}

Six of the participants reported that grammar-based examinations presented a major challenge to the implementation of CLT. As noted earlier, English curriculums in Taiwan place a strong emphasis on grammar, which is also true of national examinations. Although teachers want to spend time developing students' oral proficiency in the target language, they find it difficult to do so because of the students' previous incorrect learning strategy, which valued more in paper tests than in oral communication.

Lack of Authentic Teaching Materials

Three participants indicated that the lack of authentic teaching materials was also a constraint on their use of CLT. As pointed out by them, this is also an issue of insufficient funds to provide resources for teachers. As a result, teachers have to either pay for materials out of their own pockets or be limited to the textbook.

\section{B. Feedback from Students' Interview}

Although over half of the students showed positive attitude toward CLT, there was still certain degree of reservation and uncertainty in their response. To further understand what students felt in the CLT classroom, 12 students (4 males and 8 females) were chosen for a ten-minute interview, four each from three universities. They were labeled as S1.S2.S3 ......S12. S1 to S4 are male students. S5 to S12 are female students. The interview questions were primarily from the questionnaire and the focus was on the four domains--- teacher/student roles, peer/teacher correction, group/ pair work, and grammar. Most of them agreed that language classes should be student-centered and that teachers should help students develop sociolinguistic competence as facilitators. But some participants expressed their worry about local teachers' English proficiency when interacting with students in the classroom. Four of the participants showed their strong willingness, if possible, to be taught by foreign teachers. One of the female students explained her expectations by saying that foreign teachers could teach authentic and standard English due to their language ownership.

S5: I wish all my teachers were all native speakers, because it provides me with more chances to use English. Most of the teachers are local teachers, I know they are very good teachers, too. But, I still hope that our department can employ more foreign teachers.

Six of the participants were dubious about non-native English teachers in terms of their pronunciation, accent, use of collocations and idioms, and cultural knowledge. They believed that native English teachers would provide them genuine "foreign models." Two of the male participants shared their perception toward local teachers.

S1: My English proficiency is not good. But I don't like my local English teacher's accent and pronunciation.

S4: Sometimes I ask my teacher the difference between English expression in formal and informal occasions. I have a feeling that he is not sure about his own answer.

In regards to peer/teacher correction, most agreed that teacher correction should be avoided when it interrupts the flow of communication; moreover, most favored allowing student-student correction to take place in the classroom. However, difficulties emerged when the latter was practiced in the classroom. Seven of the participants pointed out that they had trouble when conducting peer correction. One of the major factors was due to their low English proficiency. One of the participants noted that this was one of the main obstacles.

S7: I love to talk with my classmates in the class. As to peer correction, I don't think I have the ability to do it. Because my English proficiency is very low, and that is the main reason I take English as my major. Besides, will it be effective in developing our communicative competence?

As to group/pair work and grammar, most agreed that group and pair work creates a motivating environment in which explicit grammar is not the focus, and promotes a greater amount of student involvement. However, eight of the participants noted that the passive students tend to use the native language while working in groups. Two of the female participants revealed their observations in class.

S8: Group work is a very good approach to motivate students to be involved in the discussion. Some of the students are very shy and unwilling to speak in the presence of the class. It certainly increases their learning motivation and decreases their anxiety.

S12: Pair work or group work offer us opportunities to discuss in a more relaxed atmosphere, but I feel that grammatical accuracy is very important in spite of the focus being on fluency. I feel that group work is good because it is student-centered, with little teacher correction. But, I doubt its usefulness. You know, I don't know what mistakes I 
have made during our practice. If no proper correction is given by the teacher, I am afraid that I will make the same mistake next time.

In summary, despite their reservations, most of the participants agreed that group and pair work is effective in developing students' oral conversational skills because it creates a motivating environment for students to use English, promotes a greater amount of student involvement, and increases the quantity of oral/aural language practice. Moreover, it helps those students not willing to speak in front of a full class. As to student/teacher roles, most of them agreed that language classes should be student-centered, not teacher centered, allowing for more student-student interaction than teacher-student interaction; that tasks and activities should be designed based on student needs; and that teachers should help students develop sociolinguistic competence. In regards to grammar, most agreed that to develop communicative skills, explicit grammar teaching is not necessary; though grammar may be included in a communicative lesson, it is not the main goal of teaching. In addition, most agreed that teaching should emphasize language use rather than languages rules and meaning-focused activities rather than form-focused activities. Finally, concerning peer/teacher correction, most agreed that teacher correction should be avoided when it interrupts the flow of communication; however, it ought to be provided when required for effective communication. They agreed that feedback should focus on the content of the activities and the appropriateness of student responses rather than on the form of the language. Furthermore, most favored allowing student-student correction to take place in the classroom.

\section{DISCUSSION}

The results of this study on the perception of Taiwanese English teachers toward CLT reflect the results of similar studies on Chinese and other EFL teachers' perceptions of CLT (Burnaby \& Sun, 1989; Eveyik-Aydin, 2003; Karavas-Doukas, 1996). As in Burnaby and Sun, Eveyik-Aydin, and Karavas-Doukas' study on Chinese, Turkish, and Greek English teachers' attitudes, respectively, this study also showed that the participants had favorable attitudes toward CLT, despite the difficulties they encountered in adopting this approach. More specifically, analogous to Eveyik-Aydin's (2003) findings, this study also revealed that most of the participants had favorable attitudes toward these domains of CLT: group/pair work, the place of grammar, student/teacher role, and peer/teacher correction.

Although the importance of communication is generally accepted by teachers and students alike, researchers indicated that Asian learners seem reluctant or unwilling to communicate using the target language (L2) (Tsui, 1996; Wen \& Clement, 2003). Educational traditions and Asian cultures would contribute to the problems of reticence in the classroom. Firstly, Hu (2002) pointed out the fact that learning strategies such as reception, memorization seem to encourage learners to be more passive. The job of teachers is to deliver knowledge, and the students are receivers. In their researches (Cortazzi \& Jin, 1996; Flowerdew \& Miller, 1995; Ferris \& Tagg, 1996), Asian students were seen as passive and reticent learners in the classroom; the authors linked students' learning behavior to cultural values in which teachers were seen as unquestioned authoritarians and arbiters of learning materials. It is understandable that the traditional Asian teaching culture had an impact on language learners. But, will it be objective to conclude that Asian students are all reticent and passive learners? In the present study students were very critical of their teachers and expressed negative attitude toward the traditional teaching approach in the classroom; $76 \%$ of the participants expressed favorable attitude toward CLT. The significance of this result implied that most students can be active and participative if they are given the appropriate learning environment as well as proper learning strategies. Aoki and Smith (1999) argued that cultural stereotyping would only to limit students' potential for change.

In regards to the difficulties teachers faced in implementing CLT, the findings of this study also reflect many of the same constraints found in other studies (Burnaby \& Sun, 1989; Eveyik-Aydin, 2003; Li, 1998). For example, comparable to Li's (1998) findings in her study on South Korean secondary school English teachers' perceived difficulties in adopting CLT, this study also showed that selected Taiwanese English teachers' perceived difficulties were teacher related-deficiency in spoken English, strategic and sociolinguistic competence, lack of training in CLT, and little time to develop communicative materials; student-related-low English proficiency and a passive learning style; and educational-system related-large classes, grammar-based examinations, and lack of funding. In short, the similarities in the results of this and the aforementioned studies, which were carried out in various EFL settings, including China, South Korea, Greece, and Turkey, support the general notion that EFL teachers face comparable challenges in applying the principles of CLT.

Placed in the context of CLT in Taiwan, the findings of this study along with those of previous studies and reports on CLT (Anderson, 1993; Burnaby \& Sun, 1989; Campbell \& Zhao, 1993; Liao, 2000) suggest that many of the difficulties Taiwanese English teachers encountered during and since the appearance of Li's (1984) article defending the communicative approach still remain today. Grammar-based examinations, referred to as the "piper that calls the tune" by $\mathrm{Li}(1984$, p. 13), was widely identified by this and all the other reports as a pervasive constraint on the adoption of CLT in Taiwan. Limitations associated with lack of resources and large classes identified in Burnaby and Sun's (1989) study was also found in this study. Teachers' lack of training and the lack of teaching materials reported in Anderson's article were corroborated by this study as well. Teachers' limited knowledge of culture as identified by Campbell and Zhao (1993), and teachers' lack of language proficiency as reported by Liao (2000) were constraints that most of the teachers in this study faced too.

In view of the persistence of these difficulties, the feasibility of adopting CLT in Taiwan is called into question. Is it 
possible to fully adopt CLT in the Taiwan context? Considering that CLT is an western import rooted in the western culture of learning that is in many respects in conflict with the Taiwanese culture of learning-which values teacher dominance over student-centeredness, mental activeness over verbal activeness, and student receptiveness and conformity over student independence and individuality, etc. (Hu, 2002) — is a full adoption of CLT a pedagogically sound choice? If not, does this mean that CLT ought to be abandoned?

Researchers (Campbell \& Zhao, 1993; Eveyik-Aydin, 2003; Hu, 2002; Li, 1998) have warned against a full, blind, and unbridled adoption of CLT and called attention to the need for considering the sociocultural milieu of the teaching context where CLT is being implemented. As $\mathrm{Hu}$ (2002) contends, "it is important for educational policymakers and teachers to take a cautiously eclectic approach and make well-informed pedagogical choices that are grounded in an understanding of sociocultural influences" (p. 103). Despite the aspects of the Taiwanese culture of learning that are incompatible with those of CLT, those practices of CLT suggested by Hu, such as collaborative learning and learning strategy training, that are compatible with Taiwanese traditional approaches can certainly be applied in the English classroom.

In addition, simultaneous team teaching could be one of the choices in the EFL context. It involves a NEST and a local teacher, and has proved to be effective in international school settings (Pardy, 2004). It has been implemented in TEFL or TESL situations, particularly in Japan (TAJino \& Tajino, 2000) and Hong Kong (Lai, 1999). At the tertiary level, it could be one of the recommended teaching approaches in EFL classroom. The focus is on the cooperation between native and non-native instructors, and its main goal is to assist students learning the target language more efficiently. In the present study, students preferred communicative language teaching as a means to improve their English proficiency, but they also preferred being taught by native English Speaking teachers. In terms of language performance, native teachers show more self-esteem than non-native teachers (Mahboob, 2004). Through simultaneous team teaching, language learners will benefit from both native and non-native teachers.

Cook (1999, p.185) argued that language teaching would benefit by paying attention to the L2 user rather than concentrating primarily on the native speaker. Braine (2005) argued that one group of teachers should not necessarily be superior to the other group. Ryan (1985) noted that teachers' attitude and beliefs strongly affect students' behavior. The most important thing that teachers should be concerned about is finding ways to improve their teaching skills and to effectively handle challenges such as professional training, linguistic and sociolinguistic competence, and understanding of the students' needs. To achieve this purpose, language teachers are encouraged to be engaging in such activities as self-monitoring their teaching, participating in team teaching and peer coaching. Besides, they are also encouraged to initiate an action research project, to participate in group discussions with other teachers, and to analyze case studies (Richards \& Farrell, 2005). Therefore, it is of much importance to ensure that teachers are adequately trained in language teaching methodology appropriate to a range of learner ages and stages, that teachers' own language skills are significantly enhanced, that classroom realities meet curricular rhetoric, and that students have sufficient exposure to English in instructional contexts (Nunan, 2003).

\section{CONCLUSION}

The applied linguistics community has moved on from general explorations of the applicability or difficulties of the communicative approach to task-based approach in language classroom. Language teachers throughout the world have been encouraged to reflect on their own professional development. Medgyes (1994) stated that an ideal non-native English teacher was the one who had achieved near-native proficiency in English, and an ideal native English teacher was the one who had achieved a high degree of proficiency in the learners' mother tongue. It is not who implements CLT but which strategies are used during the process of implementation. This study revealed that selected Taiwanese English teachers and students had favorable attitudes toward CLT; however, this attitude was not without reservations and even a certain amount of uncertainty. Given the incompatibility of many of CLT's practices with the Taiwanese culture of learning, it is not surprising that this should be the case. The results of this study showed that many of the difficulties encountered by the participants in implementing CLT are the same as the ones faced by Taiwanese English teachers over the last two decades. Constraints related to teachers, students, and the education system have persisted over the years and have been difficult to overcome. This state of affairs implies that there is still an urgent need for more teacher training that will prepare and equip teachers with the necessary language and pedagogical skills needed to apply CLT in the classroom. Moreover, it is of great importance for students in the EFL contexts to transform their grammar-based learning strategies into more communicative ones.

\section{APPENDIX A: COLTAS}

Please indicate your degree of agreement on the following statements: 


\begin{tabular}{|c|c|c|c|c|c|c|}
\hline & & $\begin{array}{l}\text { Strongly } \\
\text { Agree } 5 \\
\end{array}$ & $\begin{array}{l}\text { Agree } \\
4\end{array}$ & $\begin{array}{l}\text { Uncertain } \\
3\end{array}$ & $\begin{array}{l}\text { Disagree } \\
2\end{array}$ & $\begin{array}{l}\text { Strongly } \\
\text { Disagree } 1 \\
\end{array}$ \\
\hline 1. & Language classes should be student-centered, not teacher centered. & & & & & \\
\hline 2. & $\begin{array}{l}\text { Pair work activities should be avoided as it is difficult for teachers to } \\
\text { monitor each student's performance. }\end{array}$ & & & & & \\
\hline 3. & $\begin{array}{l}\text { Teacher correction should be avoided when it interrupts the flow of } \\
\text { communication via student interaction. }\end{array}$ & & & & & \\
\hline 4. & $\begin{array}{l}\text { An orderly teacher centered class is necessary for students to get } \\
\text { maximum benefit from teacher input in English. }\end{array}$ & & & & & \\
\hline$\underline{5}$. & $\begin{array}{l}\text { Students need to have immediate teacher feedback on the accuracy of } \\
\text { the English they produce. }\end{array}$ & & & & & \\
\hline 6. & Pair work develops oral conversational skills in English. & & & & & \\
\hline 7. & Group work creates a motivating environment to use English. & & & & & \\
\hline 8. & $\begin{array}{l}\text { Teachers should allow opportunity for student-student correction in } \\
\text { English. }\end{array}$ & & & & & \\
\hline$\underline{9}$. & $\begin{array}{l}\text { The major role of teachers is to transmit knowledge about language to } \\
\text { students through explanations rather than to guide them for self-learning. }\end{array}$ & & & & & \\
\hline 10. & $\begin{array}{l}\text { Teacher feedback should be mainly focused on the content of the activity } \\
\text { not on the form of language. }\end{array}$ & & & & & \\
\hline$\underline{11 .}$. & $\begin{array}{l}\text { It is of great importance that student responses in English be } \\
\text { grammatically accurate. }\end{array}$ & & & & & \\
\hline$\underline{12}$. & $\begin{array}{l}\text { Teachers should be the initiators of most interactions in English in the } \\
\text { class. }\end{array}$ & & & & & \\
\hline 13. & $\begin{array}{l}\text { To develop communicative skills, explicit grammar teaching is not } \\
\text { necessary. }\end{array}$ & & & & & \\
\hline 14. & $\begin{array}{l}\text { Emphasis should be on language use rather than language rules while } \\
\text { teaching English in the class. }\end{array}$ & & & & & \\
\hline 15. & $\begin{array}{l}\text { Pair work provides a greater amount of student involvement than a } \\
\text { teacher-led activity. }\end{array}$ & & & & & \\
\hline 16. & $\begin{array}{l}\text { Group work helps those students who are not willing to speak in front of } \\
\text { a full class. }\end{array}$ & & & & & \\
\hline 17. & $\begin{array}{l}\text { Focus on communicative competence produces linguistically inaccurate } \\
\text { speakers of language. }\end{array}$ & & & & & \\
\hline 18. & $\begin{array}{l}\text { Teachers should make an analysis of student needs in order to design } \\
\text { suitable tasks and activities in English. }\end{array}$ & & & & & \\
\hline 19. & $\begin{array}{l}\text { Group work causes a noisy classroom atmosphere which prevents } \\
\text { meaningful practice in English. }\end{array}$ & & & & & \\
\hline 20. & $\begin{array}{l}\text { Teacher feedback should be mainly focused on the appropriateness of } \\
\text { the student responses rather than the linguistic accuracy of the forms. }\end{array}$ & & & & & \\
\hline$\underline{21 .}$. & Teachers should not tolerate mistakes in English forms. & & & & & \\
\hline 22. & $\begin{array}{l}\text { Meaning focused activities are more effective to develop communicative } \\
\text { ability than form-focused activities. }\end{array}$ & & & & & \\
\hline$\underline{23}$. & $\begin{array}{l}\text { Students' attention should be drawn to the linguistic system of English } \\
\text { through direct teaching of the structures. }\end{array}$ & & & & & \\
\hline$\underline{24}$. & $\begin{array}{l}\text { Group work cannot increase the amount of English practice because the } \\
\text { students tend to use their native language while working in groups. }\end{array}$ & & & & & \\
\hline 25. & $\begin{array}{l}\text { Teacher correction should be provided only when it is required for } \\
\text { effective communication. }\end{array}$ & & & & & \\
\hline$\underline{26 .}$. & $\begin{array}{l}\text { Pair work is not an effective means of improving communication skills } \\
\text { in English. }\end{array}$ & & & & & \\
\hline 27. & $\begin{array}{l}\text { Helping students develop the use of context-appropriate language should } \\
\text { be the primary goal of language teaching. }\end{array}$ & & & & & \\
\hline$\underline{28}$. & $\begin{array}{l}\text { Students' language performance should be primarily judged by their } \\
\text { grammatical correctness. }\end{array}$ & & & & & \\
\hline$\underline{29}$. & $\begin{array}{l}\text { To learn how to communicate effectively, a considerable amount of time } \\
\text { should be spent on grammatical explanations. }\end{array}$ & & & & & \\
\hline$\underline{30 .}$. & $\begin{array}{l}\text { Since students have little information about the language, they should } \\
\text { not be allowed to correct their peers' mistakes. }\end{array}$ & & & & & \\
\hline 31. & $\begin{array}{l}\text { Most of the interaction in the class should be from students to students, } \\
\text { not from teachers to students. }\end{array}$ & & & & & \\
\hline$\underline{32 .}$. & $\begin{array}{l}\text { A teacher-directed class will motivate students to work productively } \\
\text { with English. }\end{array}$ & & & & & \\
\hline 33. & $\begin{array}{l}\text { Grammar teaching may be included in a lesson as a means of } \\
\text { communication, not as the main goal of teaching. }\end{array}$ & & & & & \\
\hline 34. & Group work increases the quantity of oral/aural language practice. & & & & & \\
\hline$\underline{35}$. & $\begin{array}{l}\text { Correction should be mainly focused on the mistakes in language } \\
\text { structures. }\end{array}$ & & & & & \\
\hline$\underline{36}$. & Pair work cannot create a motivating environment to use English. & & & & & \\
\hline
\end{tabular}

*Negative items of the scale are shown underlined here. However, no such designation was provided on the original instrument while collecting data. 


\section{APPENDIX B}

Interview Questions

In most countries where English is taught as a foreign language, teachers have had many difficulties in implementing the principles of communicative language teaching (CLT). Have you had any of the following difficulties in adopting CLT in your classroom? Or do you think any of these might be difficulties for Taiwanese English teachers in adopting CLT?

1. Teachers' deficiency in spoken English? Yes or No

2. Teachers' deficiency in strategic and sociolinguistic competence (see definition below) in English? Yes or No

3. Teachers' having little time to write and prepare communicative materials? Yes or No

4. Students' low English proficiency? Yes or No

5. Students' passive style of learning? Yes or No

6. Lack of authentic (see definition below) teaching materials? Yes or No

7. Grammar-based examinations? Yes or No

8. Large classes? Yes or No

9. The difference between EFL and ESL context (see definition below)? Yes or No

10. Teachers' lack of training in CLT? Yes or No

11. Teachers' lack of cultural knowledge? Yes or No

12. Teacher's misconceptions about CLT? Yes or No

If you answered "yes", please explain and give an example from your own teaching experiences or from that of someone else you know.

13. Have you had or have you noticed other difficulties, besides those in questions 1-12, that Taiwanese English teachers have in adopting CLT?

Strategic competence: knowing how to carry on a conversation in English and not letting it die. This is done by using various communication strategies such as asking for help, asking for repetition, asking for clarification, paraphrasing, etc.

Sociolinguistic competence: knowing what to say, how to say it, and when to say it. It is the appropriate use of the language in a given social context. For example, when you see a professor, you might greet him by saying, "Hello, Professor Chen, how are you?" This is formal. But when you see a friend you say, "Hey! What's up!" which is less formal. It also involves knowing the culture.

Authentic: real-world, real-life materials. Something you would find in society. For example, a magazine in English, a TV show in English, a story from the internet.

EFL context: EFL stands for "English as a foreign language." In a typical EFL context, English is only used in the classroom, not at home or in society. Therefore, students have a limited amount of exposure to English.

ESL context: ESL stands for "English as a Second Language." In an ESL context, English is not only used in the classroom but also outside the classroom-in restaurants, businesses, schools, TV, etc. Therefore, students have an unlimited amount of exposure to English.

\section{REFERENCES}

[1] Albarracin, D., Johnson, B. T., \& Zanna, M. P. (2005). Attitude: Introduction and Scope. Mahwah, NJ: Lawrence Eribaum Associates, Inc.

[2] Anderson, J. (1993). Is a communicative approach practical for teaching English in China? Pros and cons. System, 21, 471-480.

[3] Aoki, N., \& Smith, R. (1999). Learner autonomy in cultural context: The case of Japan. In D. Crabbe \& S. Cotterall (Eds.), Learner autonomy in language learning: Defining the field and effecting change (pp. 19-24). Frankfurt: Peter Lang.

[4] Braine, G. (Ed.). (2005). Teaching English to the world. History, curriculum, and practice. Mahwah, NJ: Laurence Erlbaum Associates.

[5] Brown, H. D. (1994). Communicative competence. Principles of language learning and teaching (3rd ed.) Oxford, UK: Oxford University Press.

[6] Burnaby, B., \& Sun, Y. (1989). Chinese teachers' views of Western language teaching: Context informs paradigm. TESOL Quarterly, 23, 219-238.

[7] Campbell, K. \& Zhao, Y. (1993). The dilemma of English language instruction in the People's Republic of China. TESOL Journal, 2(4), 4-6.

[8] Cook V. (1999). Going Beyond the Native Speaker in Language Teaching. TESOL Quarterly, 33(2), 185-209.

[9] Cortazzi, M., \& Jin, L. (1996). Cultures of learning: Language classrooms in China. In H. Coleman (Ed.), Society and the language classroom (pp. 169-206). Cambridge: Cambridge University Press.

[10] Eveyik-Aydin, E. (2003, March). EFL teacher's voice on communicative language teaching. Paper presented at the Annual Meeting of Teachers of English to Speakers of Other Languages. Baltimore, Maryland.

[11] Ferris, D., \& Tagg, T. (1996). Academic listening/speaking tasks for ESL students: problems, suggestions, and implication. TESOL Quarterly, 30(2), 297-320.

[12] Flowerdew, J., \& Miller, L. (1995). On the notion of culture in L2 lectures. TESOL Quarterly, 29(2), 345-373.

[13] $\mathrm{Hu}, \mathrm{G}$. (2002). Recent important developments in secondary English-language teaching in the People's Republic of China. Language, Culture, Curriculum, 15, 30-49.

[14] $\mathrm{Hu}, \mathrm{G}$. (2002). Potential cultural resistance to pedagogical imports: The case of communicative language teaching in China. 
Language, Culture, Curriculum, 15, 93-105.

[15] Huang, Y. K. (1990). Developing your students' communicative competence: Some practical ideas for classroom teachers. In Selected Papers from the Ninth Conference on English teaching and learning in ROC, 54-64. Taipei: The Crane Publishing Co., Ltd.

[16] Hymes, D. (1972). On communicative competence. In J. B. Pride, \& J. Holmes (Eds.), Sociolinguistic. Harmondsworth: Penguin.

[17] Karavas-Doukas, E. (1996). Using attitude scales to investigate teachers' attitude to the communicative approach. ELT Journal, 50, 187-198.

[18] Lai, M. (1999). Hong Kong: Language and education in a post-colonial era. Language, Culture Curriculum, 12(3): 191-195.

[19] Larsen-Freeman, D. (2000). Communicative language teaching. In Techniques and principles in language teaching (2nd ed.). New York, NY: Oxford University Press.

[20] Li, D. (1998). "It's always more difficult than you plan and imagine": Teachers' perceived difficulties in introducing the communicative approach in South Korea. TESOL Quarterly, 32, 677-703.

[21] Li, X. J. (1984). In defense of the communicative approach. ELT Journal, 38, 2-13.

[22] Liao, X. Q. (2000). Communicative language teaching innovation in China: Difficulties and solutions. New Zealand. (Eric Document Reproduction Service No. ED 443294 )

[23] Mahboob, A. (2004). Native or nonnative: What do students enrolled in an Intensive English Program think? In L. Kamhi-Stein (Ed.), Learning and teaching from experience” Perspectives on nonnative English-speaking professionals. Pp.100-120. Ann Arbor: University of Michigan Press.

[24] Matsurra, H., Chiba, R., \& Hilderbrandt, P. (2001). Beliefs about learning and teaching communicative English in Japan. JALT Journal, 23, 69-89.

[25] McManus, Walter S. (1985). "Labor Market Assimilation of Immigrants: The Importance of English Language Skills." Contemporary Policy Issues 3,77-89.

[26] Medgyes, P. (1994). The non-native teacher, London: Macmillan Publisher.

[27] Nunan D. (2003). The Impact of English as a Global Language on Educational Policies and Practices in the Asia-Pacific Region. TESOL Quarterly. 37(4), 589-613.

[28] Pardy, D. (2004). The perceived effectiveness of simultaneous team-teaching in a dual language programme. Journal of Research in International Education, 3(2),207-224.

[29] Rao, Z. (2002). Chinese students' perceptions of communicative and non-communicative activities in EFL classroom. System, $30,85-105$.

[30] Richards, J. C., \& Farrell, T. S. C. (2005). Professional development for language teachers: Strategies for teacher learning. New York: Cambridge University Press.

[31] Ryan, P.M. (1998). Cultural knowledge and foreign language teachers: A case study of a native speaker of English and a native speaker of Spanish. Language, culture, and curriculum. 11(2), 135-150

[32] Tajino, A. \& Tajino, Y. (2000). Native and non-native: what can they offer? Lessons from team-teaching in Japan. ELT Journal, 54(1),3-11.

[33] Tsui, A. B. M. (1996). Reticence and anxiety in second language learning. In K. M. Bailey \& D. Nunan (Eds.), Voices from the language classroom: Qualitative research in second language education (pp. 145-165). New York: Cambridge University Press.

[34] Wang, L.(1994). Theory and practice: A study of EFL methodologies employed by student teachers in junior high school. Unpublished master's thesis, National Kaohsiung Normal University, Kaohsiung, Taiwan.

[35] Wen, W. P., \& Clement, R. (2003). A Chinese conceptualization of willingness to communicate in ESL. Language, Culture and Curriculum, 16(1), 18-38.

[36] Yang, L. (1978). Pattern Drills: Design and application. Journal of the Chinese Language Teachers Association. 13(2), 110-117.

Kun-huei Wu received his Ph.D. from Tamkang University in Taiwan in 2004. He has been teaching English at institutional and academic levels for the past 12 years. Currently, he is an assistant professor in the Department of English; chairman of the Foreign Language Center. His main interests include English language teaching and cross-cultural studies. 